\title{
Análisis preliminar del proceso de reasentamiento del poblado de Chamela, Costa Sur de Jalisco
}

\section{Preliminary Analysis of the Resettlement Process of the Locality of Chamela in the Southern Coastal region of Jalisco, Mexico}

Esmeralda Azucena Mastache De los Santos

Investigadora Independiente

azu.mastache@gmail.com

Peter R.W. Gerritsen

Universidad de Guadalajara, Centro Universitario de la Costa Sur, Departamento de Ecología y Recursos Naturales

petergerritsen@cucsur.udg.mx

DOI: I0.2490I/rehs.v40i159.436

\section{(c)) EY-NG}

Análisis preliminar del proceso de reasentamiento del poblado de Chamela, Costa Sur de Jalisco por Esmeralda Azucena Mastache De los Santos se distribuye bajo una Licencia Creative Commons Atribución-NoComercial 4.o Internacional.

Fecha de recepción: 24 de mayo de 2018

Fecha de aprobación: 20 de febrero de 2019 


\section{RESUMEN:}

El turismo se puede considerar como una estrategia para la acumulación capitalista en los espacios rurales, al expulsar a las comunidades de sus territorios y despojarlas de sus medios de vida. En este artículo documentamos el caso de la reubicación de Chamela, un poblado en la zona litoral de Jalisco conformado por aproximadamente cincuenta familias de pescadores, las cuales fueron desalojadas para la construcción de un complejo turístico llamado Zafiro, que abarcará aproximadamente 9io ha. El caso de Chamela refleja cómo el reasentamiento por proyectos turísticos es una maniobra para romper con la estructura interna de la comunidad, socavar su autonomía económica y generar dependencia a estas empresas de servicios, que reconfiguran completamente el territorio en función de sus necesidades.

Palabras clave:

Chamela, Ecología Política, reubicación, actores sociales, privatización.

\section{ABSTRACT:}

Tourism can be considered a strategy for capitalist accumulation in rural areas where established communities are evicted from their territories, depriving local people of their livelihoods. This article documents the case of the resettling of Chamela, a locality in the coastal zone of Jalisco in western Mexico that consists of some fifty families of fishermen who were expelled so that a tourist complex called Zafiro could be constructed there. This resort covers approximately 9 IO hectares. The case of Chamela reflects how forced resettlement due to tourism projects is a strategy that weakens the internal organizational structure of communities, undermines their economic autonomy and generates dependence on service companies that completely reconfigure the territory according to their needs.

Keywords:

Chamela, Political Ecology, resettlements, actors, privatization.

\section{Introducción ${ }^{\underline{1}}$}

Las costas del Pacífico mexicano, además de ser reconocidas por su singular belleza paisajística, son importantes por ser un área de asentamiento de importantes centros poblacionales y por la diversidad de vegetación y fauna en sus ecosistemas, donde destacan la selva baja y los manglares. El litoral correspondiente al estado de Jalisco no se excluye de esta descripción, ya que tiene una 
alta biodiversidad de la que hacen uso y manejo diversas poblaciones, siendo la agricultura, la ganadería y la pesca artesanal las principales actividades económicas (Maldonado et al.20I5).

No obstante, la adopción de políticas neoliberales en el territorio mexicano ha promovido el turismo sobre las demás actividades productivas de las regiones costeras y, para implementar estas actividades, se recurre a la apropiación de espacios públicos para construir grandes infraestructuras, excluyendo a la población local de sus medios de subsistencia, patrimonios culturales y formas de organización social ( $\underline{\text { Paz 20I2 }}$ ).

En la costa de Jalisco, como reflejo de lo que sucede en el resto del país, las inversiones turísticas acaparan grandes extensiones de terreno, por lo que recurren al reasentamiento de las poblaciones para poder asegurar la exclusividad de sus propiedades (Martínez y Corgos 20I4). Los reasentamientos tienen implicaciones económicas, políticas, ambientales, sociales y culturales en las comunidades afectadas (Martínez 20iz).

El reasentamiento del poblado de Chamela, en el municipio de La Huerta, es un caso que evidencia cómo el turismo es un mecanismo de privatización con impactos multidimensionales que se replican a lo largo de las playas jaliscienses (Martínez y Corgos 20I4). Por lo anterior, el objetivo del presente trabajo es realizar un estudio exploratorio para analizar el proceso de reasentamiento del poblado de Chamela, desde la perspectiva de los habitantes afectados. Para lograrlo, buscamos describir la conformación histórica del poblado y documentar su proceso de reasentamiento y, con ello, identificar las repercusiones y las percepciones de sus pobladores a partir de la reubicación.

\section{Acercamiento teórico}

El análisis del tema del reasentamiento involuntario por proyectos de desarrollo turístico que realizamos en este texto, lo hacemos desde el enfoque de la Ecología Política (EP) entendida como el estudio de los conflictos ambientales o ecológico-distributivos, por la competencia por el uso, acceso y control de territorios y de los llamados recursos naturales, entre actores con relaciones desiguales de poder (Martínez-Alier 2006).

No obstante, para este abordaje debemos comprender los mecanismos del sistema socioeconómico capitalista para generar excedentes de capital y de fuerza de trabajo sobreexplotando los bienes naturales, mediante una serie de ajustes o arreglos espaciotemporales (Harvey 2004) a través de la incorporación de nuevos territorios, relaciones sociales o mercados futuros, de tal manera que siga funcionando la maquinaria extractiva; un proceso al que Harvey (2004) ha denominado acumulación por despojo.

Aquí resalta el turismo como uno de los diversos mecanismos para el despojo y la privatización del territorio en los espacios rurales, recurriendo a la reubicación forzada de poblaciones como una estrategia para su imposición sin importar los conflictos socioecológicos que generan (Fletcher 2016, Vilchis et al.2016). Por ello, estudiar el fenómeno turístico desde la EP, como menciona Fletcher (2016), "ofrece un análisis matizado de la compleja interconexión entre los procesos políticos, sociales, económicos y ecológicos que intervienen en el desarrollo 
del turismo, a través de la vinculación entre los distintos agentes que operan a diferentes escalas" $(2016,27)$.

Tomamos el caso de la costa jalisciense en México, donde en las últimas décadas han proliferado las inversiones turísticas que desaparecen las constelaciones culturales y desfiguran el paisaje natural de sus litorales, dando pie a potenciales conflictos en esos territorios.

\section{El turismo como mecanismo de despojo}

En el marco de la economía neoliberal que tiene al crecimiento financiero como principal motor de desarrollo, el turismo se ha consolidado como un mecanismo predilecto para la acumulación, por su poder de atracción de capitales extranjeros (Harvey 2004) que buscan la apropiación e incorporación de bienes naturales a la estructura capitalista, mediante su privatización (Cañada 2016, Vilchis et al.2016). Así, el turismo se expande por diversas partes del mundo, definiendo pautas de desarrollo económico en un gran número de regiones y localidades como lo ha hecho en América Latina (Palafox et al. 20II).

Los proyectos turísticos suelen imponerse mediante el expolio de la tierra (Cañada 20i6, Murray 2016), reconfigurando el territorio en función de las necesidades de esta actividad, marcando nuevas dinámicas que reorganizan y redistribuyen el espacio, lo que genera nuevos hábitos y prácticas culturales (guilar et al.20I5, Palafox et al. 20II, Cruz-Coria et al. 20I2) que derivan, en la mayoría de los casos, en conflictos socioecológicos ( $\underline{\text { Paz 2OI2 }})$.

Las afectaciones en la dimensión ecológica aparecen desde la construcción de los inmuebles, para lo cual se destruyen ecosistemas como manglares, humedales o bosques, degradando los suelos, generando y acumulando residuos sólidos, además de la contaminación y sobreexplotación de los cuerpos de agua (Cordero et al.2002, Cañada y Gascón 2016). Respecto al líquido vital, éste se convierte en objeto de competencia entre la población local -que lo emplea para uso doméstico o agropecuario- y los nuevos complejos que lo requieren desde la construcción hasta la operación: aseo de los usuarios, spa, albercas, mantenimientos de jardines, campos de golf, entre otros (Cañada 20i6).

El turismo acapara los recursos (naturales, energéticos y fuerza de trabajo), y genera disputas entre sectores sociales por el control, gestión y acceso a tales bienes (Cañada y Gascón 20i6), siendo los habitantes locales los más afectados, ya que son expulsados de sus lugares de origen o, en todo caso, contratados en los niveles más bajos de la escala laboral en condiciones de precarización con salarios bajos, irregularidad en los pagos, subcontrataciones, acoso policial, inseguridad y riesgo laboral (Cañada 2016).

En contraste, por el turismo también llega población de mayor poder adquisitivo (tanto de los usuarios como de quienes trabajan en puestos gerenciales), que gozan de otras garantías y beneficios que fueron arrebatados a los residentes locales, esto aumentó y recrudeció la desigualdad e injusticia social. La figura I, muestra la multidimensionalidad del turismo como una actividad que, al integrarse en una región, redefine las dinámicas existentes en las distintas dimensiones que la integran. 
Figura I. Multidimensionalidad del turismo

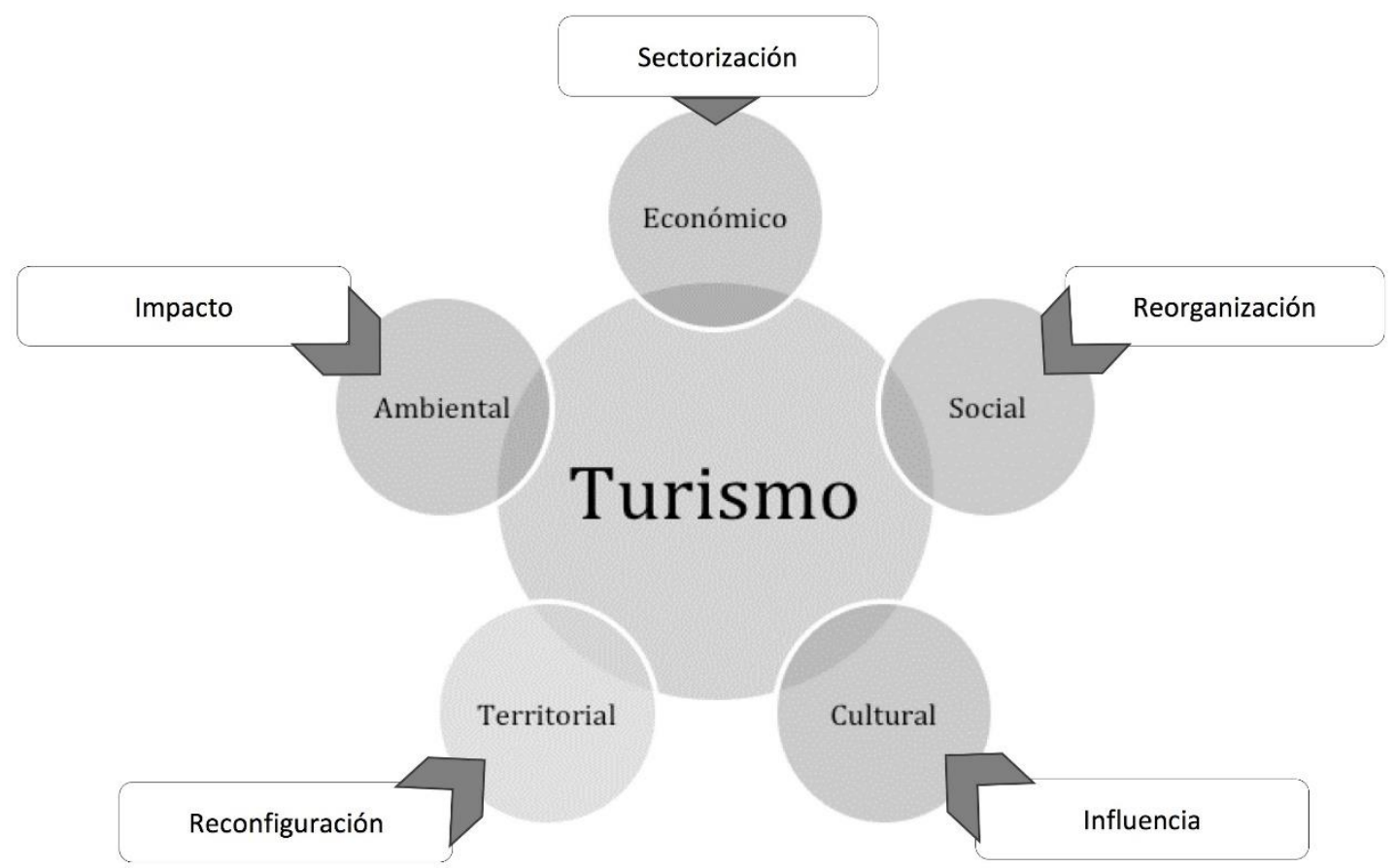

Fuente: elaboración propia.

Respecto al impacto en la dimensión cultural, el turismo impone nuevos patrones de conducta y consumo, y acapara espacios simbólicos alterando la identidad de los habitantes locales. En la dimensión social, esta actividad terciaria reorganiza completamente las redes y las relaciones de los habitantes locales, además de que pierden el control sobre los medios de producción y quedan subordinados a los nuevos actores. Asimismo, en lo económico, el turismo entra en competencia con otros sectores por el uso de diferentes recursos (naturales, energéticos, fuerza de trabajo, capital público y privado para la inversión, etcétera) reestructurando su asignación de manera desigual, obteniendo, la mayoría de las veces, ventaja sobre ellos (Cañada y Gascón 2016).

Como se mencionó previamente, el impacto ambiental que se genera por el turismo comienza a visibilizarse desde su implementación hasta su ejecución, no obstante, según sean los principios u objetivos del proyecto turístico, pueden afectar el entorno o mitigar con medidas preventivas. Por último, en lo que corresponde a lo territorial, la suma de todas las modificaciones mencionadas resulta en una reconfiguración de los espacios y sus dinámicas internas con la aparición de nuevos actores y la reorganización de las actividades en función de intereses capitalistas.

El fenómeno turístico en América Latina y el caso de México 
América Latina, una de las regiones del planeta con más biodiversidad, se ha convertido en uno de los principales lugares para expropiar y mercantilizar los bienes naturales a manos de corporaciones trasnacionales que han encontrado en el turismo, un nuevo mecanismo de despojo y privatización del territorio para la expansión capitalista (Composto 20Io, Svampa 20II, Vilchis et al.20I6).

El papel del Estado ha sido fundamental para afianzar la maquinaria extractiva, creando las condiciones de legalidad al seguir los lineamientos internacionales, que facilitan la inserción de inmobiliarias turísticas que desplazan comunidades completas y transforman totalmente sus modos de relacionarse con el entorno, además de permitir la apertura a la exploración de nuevos lugares para fines distintos al ocio (Cañada y Gascón 20I6, Cruz-Coria et al. 20I2, Vilchis et al.2016). Lo anterior explica por qué el turismo se ha convertido en un eje prioritario en la agenda neoliberal de América Latina (Navas y Blázquez 20i6).

En el caso particular de México, la legislación ha otorgado garantías a empresas extranjeras para legitimar la cesión de derechos de uso público de la tierra al desparecer la tenencia ejidal mediante la reforma del artículo 27 de la Constitución Mexicana en I992, en la que se decretó el fin del reparto, que abrió la posibilidad jurídica de convertir las tierras ejidales y comunales en propiedad privada y de los campesinos en propietarios (Roux 2012). Complementario a lo anterior, se decretó la Ley de Inversión Extranjera y se diseñaron programas nacionales que propiciaban la implementación de proyectos turísticos, sin visualizar sus consecuencias.

Estos amparos legales han propiciado el ambiente necesario para la imposición de la actividad turística, estableciendo el dominio del capital sobre la tierra, los bienes naturales y patrimonios culturales bajo una dinámica de subsunción (Vilchis et al.2016) esto dio lugar a nuevas formas de despojo en el territorio mexicano. Como pasó con las playas del Caribe, las del Pacífico mexicano también se convirtieron en una solución espacio-temporal para el capital internacional (Harvey 2004). Resultado de lo anterior, actualmente la actividad turística constituye la causa de afectación en $7 \%$ del total de casos de conflictos socioambientales diagnosticados en el país ( $\underline{\text { Paz 20I2) }}$.

\section{Acerca de los reasentamientos}

El reasentamiento de comunidades de manera involuntaria es una estrategia que aplican los desarrollistas del turismo, como muchos otros megaproyectos, para apropiarse y privatizar espacios habitados y subsumirlos a las dinámicas del capital (Cernea 200I, Cruz-Coria et al.2012). El concepto de reasentamiento se asocia con otros dos términos: desalojo y reubicación, que vale la pena definir para su posterior uso en este texto.

El desalojo consiste en la expropiación de un terreno mediante la intervención de la fuerza pública (lo que implica actos violentos) al considerar que los pobladores no tienen ningún derecho sobre el territorio (Victoria y Molina 2003). Cernea (200I) considera el desalojo como la primera etapa del desgarramiento social. Por otra parte, la reubicación determina la 
adjudicación de un lote en una urbanización, donde el poblador deberá iniciar su proceso de asentamiento y construcción de la vivienda por sus propios medios (Victoria y Molina 2003).

En este texto hablaremos de reasentamientos involuntarios, como la acción en la que un conjunto de personas se ve compelido a abandonar el espacio que habitan para trasladarse a otra área (Macías 200I) y puede tener diferentes causas: por fenómeno natural o alto riesgo, por violencia o por proyectos de desarrollo (véase tabla I).

Tabla I. Diferentes causas del reasentamiento

\begin{tabular}{|l|l|}
\hline $\begin{array}{l}\text { Causa del } \\
\text { reasentamiento }\end{array}$ & Descripción \\
\hline $\begin{array}{l}\text { Por fenómeno } \\
\text { natural o alto riesgo }\end{array}$ & $\begin{array}{l}\text { Se contempla para los casos donde el asentamiento se ha establecido } \\
\text { en terrenos inundables o inestables con riesgo de deslizamientos o de } \\
\text { anegación. De igual manera, si hubo catástrofe por fenómenos } \\
\text { naturales como huracanes o sequías. }\end{array}$ \\
\hline Por violencia & $\begin{array}{l}\text { Como resultado de la ocurrencia de una acción violenta y conflictos } \\
\text { armados que ponen en riesgo la vida de la comunidad o de alguno de } \\
\text { sus miembros. La población se ve obligada a salir de su lugar de } \\
\text { habitación y se ubica, generalmente, en zonas urbanas, lo que provoca } \\
\text { los llamados desplazamientos forzosos o forzados.* }\end{array}$ \\
\hline $\begin{array}{l}\text { Por proyectos de } \\
\text { desarrollo }\end{array}$ & $\begin{array}{l}\text { Son determinados por la existencia de proyectos que responden a } \\
\text { indicadores macroeconómicos con un supuesto beneficio nacional, } \\
\text { que requieren importantes cambios en el uso de la tierra y del agua. } \\
\text { Entre éstos encontramos: represas (para el riego, la energía } \\
\text { hidroeléctrica y el agua potable); rutas de transporte (ferrocarriles, } \\
\text { carreteras, aeropuertos, líneas de transmisión, canales de riego); } \\
\text { nuevos puertos y centros urbanos; infraestructura civil (sistemas de } \\
\text { alcantarillado, caminos de entronque y vías subterráneas); nuevas } \\
\text { minas; parques o zonas industriales; protección para las reservas } \\
\text { forestales o parques nacionales, y complejos turísticos. }\end{array}$ \\
\hline
\end{tabular}

*El desplazamiento forzado sucede después de la ocurrencia de una acción violenta, que pone en riesgo la vida de la comunidad o alguno de sus miembros (Ibid.)

Fuente: elaboración propia con base en Cernea 200I, Macías 200I, Victoria y Molina 
Reasentamientos por proyectos de desarrollo

En este estudio abordamos el tipo de reasentamiento por proyectos de desarrollo, en específico, por complejos turísticos. Cabe recordar que los proyectos por desarrollo, son el resultado de una práctica constitutiva de proyectos políticos y económicos neoliberales bajo el argumento de dar prioridad a necesidades nacionales.

Los reasentamientos se basan en la desigualdad de poder entre los participantes, ya que los reubicados no manejan los mismos recursos adquisitivos que los empresarios, porque generalmente son poblaciones vulnerables: grupos situados en posición de marginalidad social, económica, geográfica y política, siendo actores pasivos en el proceso ( $\underline{\text { Fenner 20I2}}$, Smith 200I).

Los reasentamientos involuntarios generan una serie impactos y afectaciones en el ámbito social, cultural y económico de una comunidad, que en primera instancia no son visibilizados, pero, conforme pasa el tiempo, el efecto acumulativo deja ver lo que Cernea (200I) llama el desgarramiento del tejido social, creando una sensación de alienación, desesperanza e impotencia. En la tabla 2 mencionamos los posibles impactos generados para cada dimensión de la comunidad afectada.

Tabla 2. Posibles impactos sociales, culturales y económicos de los reasentamientos

\begin{tabular}{|c|c|c|}
\hline Dimensión & Impactos & Consecuencias \\
\hline Social & $\begin{array}{l}\text { - Se dispersan los grupos de } \\
\text { parentesco y los sistemas } \\
\text { familiares. } \\
\text { - Se desintegran las redes sociales } \\
\text { informales y las asociaciones } \\
\text { formales. } \\
\text { - Los sistemas tradicionales de } \\
\text { autoridad y de administración } \\
\text { pierden sus líderes. }\end{array}$ & $\begin{array}{l}\text { - Debilitamiento de la } \\
\text { cohesión social } \\
\text { - Disminuye la } \\
\text { capacidad de acción } \\
\text { colectiva } \\
\text { - Aumenta la tensión } \\
\text { - } \text { Msicológica } \\
\text { Marginación }\end{array}$ \\
\hline Cultural & $\begin{array}{l}\text { - Se abandonan espacios simbólicos } \\
\text { como los santuarios, los } \\
\text { cementerios ancestrales o las } \\
\text { montañas, ríos o senderos } \\
\text { sagrados. } \\
\text { - Se quiebra el vínculo físico y } \\
\text { psicológico con el pasado. } \\
\text { - Se borran las raíces de la } \\
\text { identidad cultural de la población. }\end{array}$ & \\
\hline
\end{tabular}




\begin{tabular}{|c|c|c|}
\hline Económico & $\begin{array}{l}\text { - Se desmantelan los sistemas de } \\
\text { producción. } \\
\text { - Se interrumpen los nexos } \\
\text { comerciales entre productores y } \\
\text { consumidores. } \\
\text { - Se desorganizan los mercados } \\
\text { locales. }\end{array}$ & $\begin{array}{ll}\text { - } & \text { Desempleo } \\
\text { - } & \text { Inseguridad } \\
& \text { alimentaria } \\
\text { - } & \text { Empobrecimiento }\end{array}$ \\
\hline
\end{tabular}

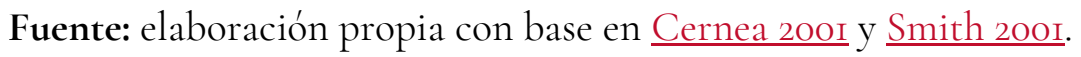

En la mayoría de los casos, las consecuencias negativas del desalojo se han visto agravadas por la ausencia de una estrategia para corregir los problemas ocasionados, siendo el acceso a la tierra un factor decisivo, dado que la gran mayoría de los desalojados suelen ser familias campesinas, por lo que restaurar su potencialidad productiva depende esencialmente de la disponibilidad de sus medios de producción.

Por todo lo anterior, queda claro que los reasentamientos involuntarios son mucho más que un simple traslado de un sitio a otro, son un proceso que implica la recomposición de la comunidad atendiendo las estructuras económicas, culturales y sociales que salen afectadas, las cuales debido a su desarticulación, pueden engendrar un grave síndrome de dependencia a otras

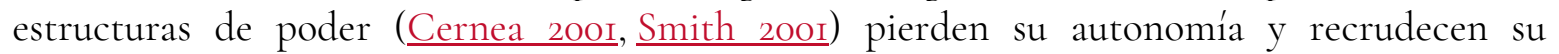
vulnerabilidad.

Diseño de estudio

\section{Área de estudio}

El poblado de Chamela pertenece al municipio de La Huerta, en la región Costa del estado de Jalisco, en el Pacífico mexicano. Se ubica al sur de la Bahía de Chamela, aproximadamente a izo $\mathrm{km}$ al norte de Manzanillo, Colima y a $200 \mathrm{~km}$ al sur de Puerto Vallarta, a un costado de la

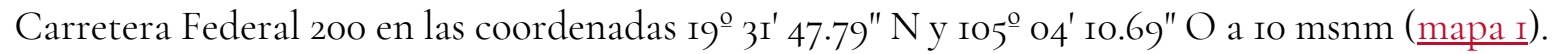
El último conteo de población por INEGI en el año 20I0, registró I43 personas distribuidas en 33 viviendas.

Mapa i. Ubicación geográfica de la localidad de Chamela, municipio de La Huerta, Jalisco, México 


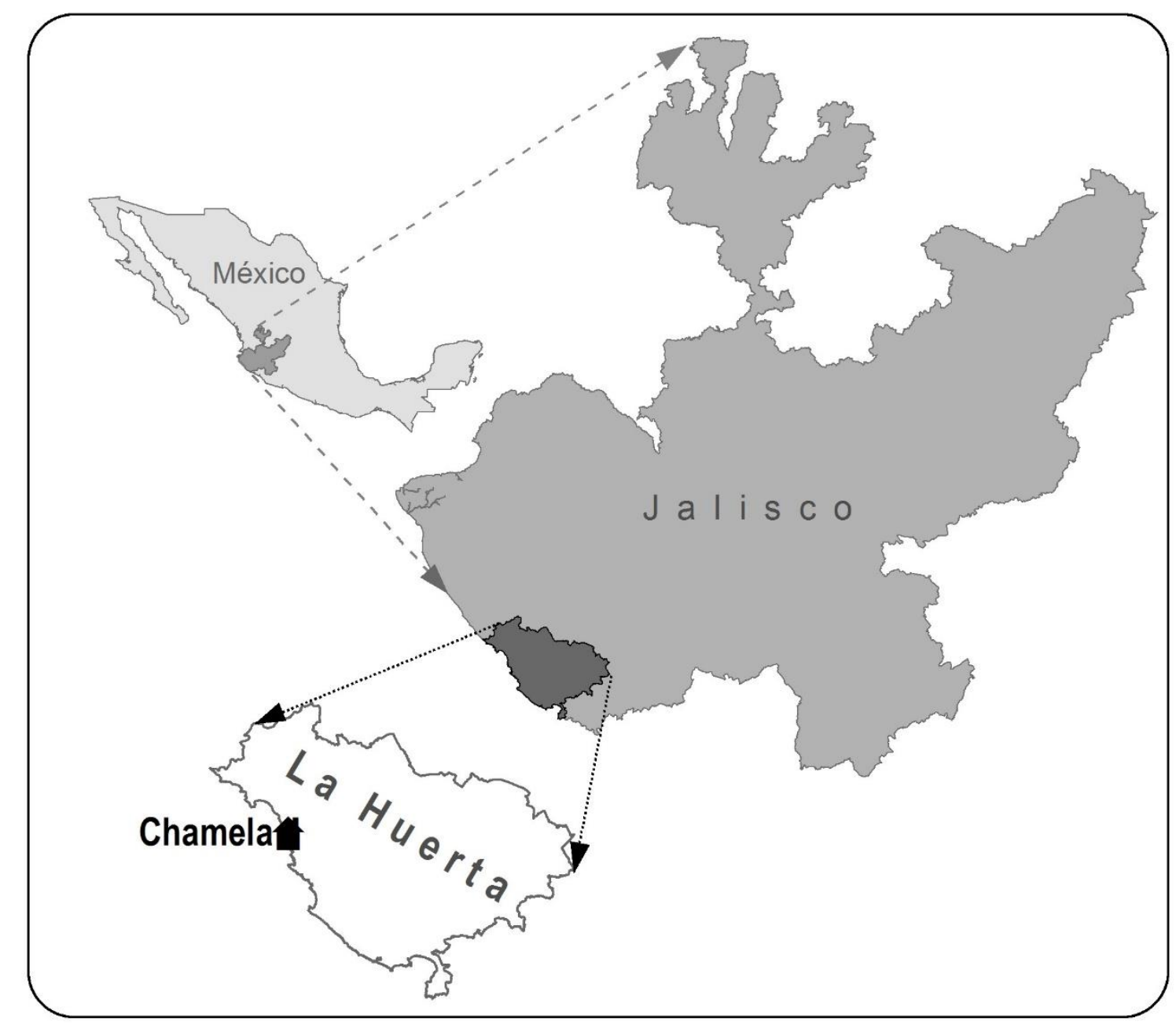

\section{Elaborado por Óscar Balcázar Medina y Juan Manuel Rodríguez Gómez, DERN, CU Costa sur, Universidad de Guadalajara}

Chamela se encuentra en una región con un relieve dominado por lomeríos y algunas planicies aluviales y manglares cerca de la desembocadura del arroyo Chamela. El tipo de vegetación principal es el bosque tropical caducifolio (BTC) que comparte con selva mediana subperenifolia, la vegetación de arroyo, el manglar, la vegetación riparia, el carrizal y la vegetación acuática (Ceballos y García 20io). Al igual que la flora, la fauna presente en el área es muy diversa, con especies de aves residentes y migratorias, anfibios, reptiles y mamíferos.

\section{Metodología}

Nuestro estudio se llevó a cabo en noviembre de 2017 y para analizar el caso del reasentamiento del poblado de Chamela se emplearon los siguientes métodos.

- Revisión documental. Se realizó una consulta exhaustiva de fuentes bibliográficas, hemerográficas y cartográficas, relacionadas con la historia ambiental en la costa de 
Jalisco. Nos enfocamos principalmente en la región donde se ubica el poblado de Chamela. Este paso fue esencial también para entender la cronología del proceso de reasentamiento que se vivió en Chamela y situarlo en un marco más amplio como lo es el fenómeno de la privatización de las costas jaliscienses.

- Entrevistas a informantes clave. Se llevaron a cabo entrevistas a profundidad con los miembros de cuatro familias afectadas, en torno al tema del reasentamiento y sus percepciones respecto a los cambios que acontecieron a partir de este suceso. Además, se realizaron charlas informales con diversas personas de la comunidad.

- Recorrido de campo. Se realizó un recorrido en lancha para ubicar y reconocer las playas que fueron privatizadas y a las que anteriormente tenían acceso los pobladores de Chamela. Asimismo, esta actividad sirvió de apoyo para describir las características ambientales de la región. También se realizaron visitas a la actual unidad habitacional, para conocer la infraestructura y condiciones actuales de vivienda.

Resultados

Acerca del poblado de Chamela

El poblado de Chamela colinda al sur con la Reserva de la Biosfera Chamela-Cuixmala (RBCC), reconocida por sus investigaciones en torno a la selva baja (el bosque tropoical caducifolio) y por la conservación de estas áreas en donde habitan gran diversidad vegetal y gran cantidad de

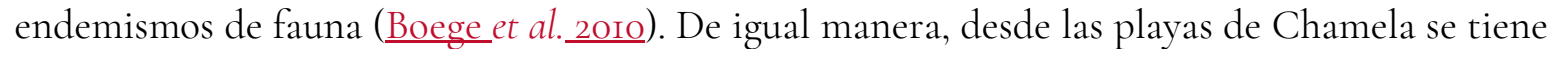
acceso a las islas La Pajarera, Cocinas, Mamut, Colorada, San Pedro, San Agustín, San Andrés y Negrita, y los islotes Los Anegados, Novillas, Mosca y Submarino, reconocidos como área natural protegida con el carácter de Santuario.

La mayoría de las familias, que poblaron Chamela, llegaron a la región hace aproximadamente 50 años, desde entonces, la principal actividad productiva desarrollada fue la pesca artesanal y la agricultura, complementada con otros trabajos temporales como la venta de alimentos y paseos en lancha para el turismo local, regional y nacional, que actualmente ya no llegan a la zona porque está restringido el paso.

La infraestructura pública con la que contaron los habitantes de Chamela fue un jardín de niños, una escuela primaria y una iglesia; respecto a las viviendas, los materiales con las que estaban construidas eran lonas de plástico, palos y ladrillos. A continuación se presenta un recuento de los principales acontecimientos históricos que influyeron en el poblamiento de Chamela y sus principales cambios en el entorno natural, poniendo especial énfasis en el reasentamiento involuntario que realizaron debido a la puesta en marcha del proyecto turístico Zafiro.

\section{Conformación histórica del poblado de Chamela}

En la Bahía de Chamela, donde se ubica la localidad del mismo nombre, no se han registrado vestigios que confirmen la existencia de asentamientos prehispánicos, sin embargo, no se descarta que haya sido lugar de paso para grupos de cazadores-recolectores (Mountjoy 20I5). 
Cuando llegaron los españoles, en I524, al mando de Francisco Cortés de San Buenaventura, exploraron la zona en busca de posibles territorios mineros, al no encontrarlos quitaron su atención del litoral durante casi tres siglos (Bye et al. 2002).

A mediados del siglo XIX, la región comenzó a ser habitada mediante hacendados dedicados a la agricultura, la ganadería y la extracción de sal, como la hacienda Cuixmala (de aproximadamente 90,ooo ha), creada en I859 abarcaba desde el actual poblado Nacastillo hasta Cuixmala (Castillo et al.2005). Para el siglo XX, en 1945, quedaban registradas solamente 25 mil hectáreas de la hacienda Cuixmala en propiedad de la familia De Landeros, que repartió 5 mil hectáreas en 26 lotes a distintos beneficiaros (Proceso 1997), para evitar la conformación de ejidos por la reforma agraria que acontecíaen aquellos años (Ávila y Luna 20rz). Las 20 mil hectáreas restantes quedaron en posesión de una sola persona que posteriormente las vendió a un particular llamado Antonio Urquiza, quien la independizó del poblado de Cuixmala (Martínez 2003).

Entre 1960 y 1970 se intensificó la afluencia de gente proveniente de otros estados. En el contexto de Programa de Progreso Marítimo, denominado Marcha al Mar, impulsado por el presidente Adolfo Ruiz Cortines (1952-1958), se creó en 1953, la Comisión de Planeación de la Costa de Jalisco, como parte de un proceso de colonización agraria de la costa de Jalisco, impulsada por el reparto de tierras (Martinez 2003, Ávila y Luna 2003).

La gente que migraba a la región, lo hacía para emplearse en diversos proyectos como la edificación de la Estación de Biología de la Universidad Nacional Autónoma de México (UNAM) en I97I, la construcción de la Carretera Federal 200 Melaque-Puerto Vallarta en i972, y de algunos hoteles como el de Careyes (Martínez 2003).

Es así como en los setenta, en los terrenos privados de la familia Urquiza se comenzaron a avecindar familias removiendo la vegetación para establecer sus viviendas, abrir brechas para transporte y llevar a cabo actividades agrícolas; factores que transformaron paulatinamente el ecosistema (Castillo et al.2005). Con el tiempo, las personas se fueron alojando de manera definitiva y desarrollaron la pesca como actividad productiva principal, hasta conformar el actual poblado de Chamela. Por este aumento demográfico se demandaron otros servicios como el suministro de agua potable, la instalación de drenaje y de electricidad. Martínez $\underline{(2003)}$ menciona que, ante esta situación, el propietario Urquiza decidió ceder una parte de su terreno al gobierno municipal de La Huerta para que perteneciera al poblado.

Dos décadas después, en los ochenta, el empresario James Goldsmith compró terrenos en la región de la bahía de Chamela en distintas etapas hasta adueñarse de aproximadamente de 20,00o ha (Proceso 1997), de éstas promovió 9,00o ha como reserva privada, con un decreto que consiguió en diciembre de 1993, con la categoría de Reserva de la Biósfera, que incluía I,60o ha de la Estación Biológica de la UNAM (que fueron donadas por Urquiza), 70o ha de la Universidad de Guadalajara y i,7oo ha aportadas por la entonces Secretaría de Agricultura y Recursos Hidráulicos; un total de I3,I42 ha (astillo et al. 2005). 
Como podemos observar, la colonización de la región donde se encuentra el poblado Chamela se dio de forma espontánea (Martínez 20rz), es decir, como un proceso paulatino en el que las personas buscaban un lugar para habitar y generaban las condiciones para hacerlo. Sin embargo, los pocos derechos, que pudieron tener los habitantes de Chamela sobre sus tierras, se han perdido por la privatización y la prohibición al uso libre de los espacios que en algún tiempo fueron comunes, además de la amenaza de daños a los ecosistemas, la vegetación y la fauna por los nuevos desarrollos turísticos.

En la figura 2 se presenta una línea del tiempo con las principales etapas y procesos sociopolíticos que conformaron el poblado de Chamela que, en el año 2oro, fue desalojado y reubicado por la empresa Invermar, un corporativo que tiene planeado edificar en esos territorios el Proyecto Zafiro y excluir a quienes los han habitado por décadas.

Figura 2. Conformación histórica del poblado de Chamela

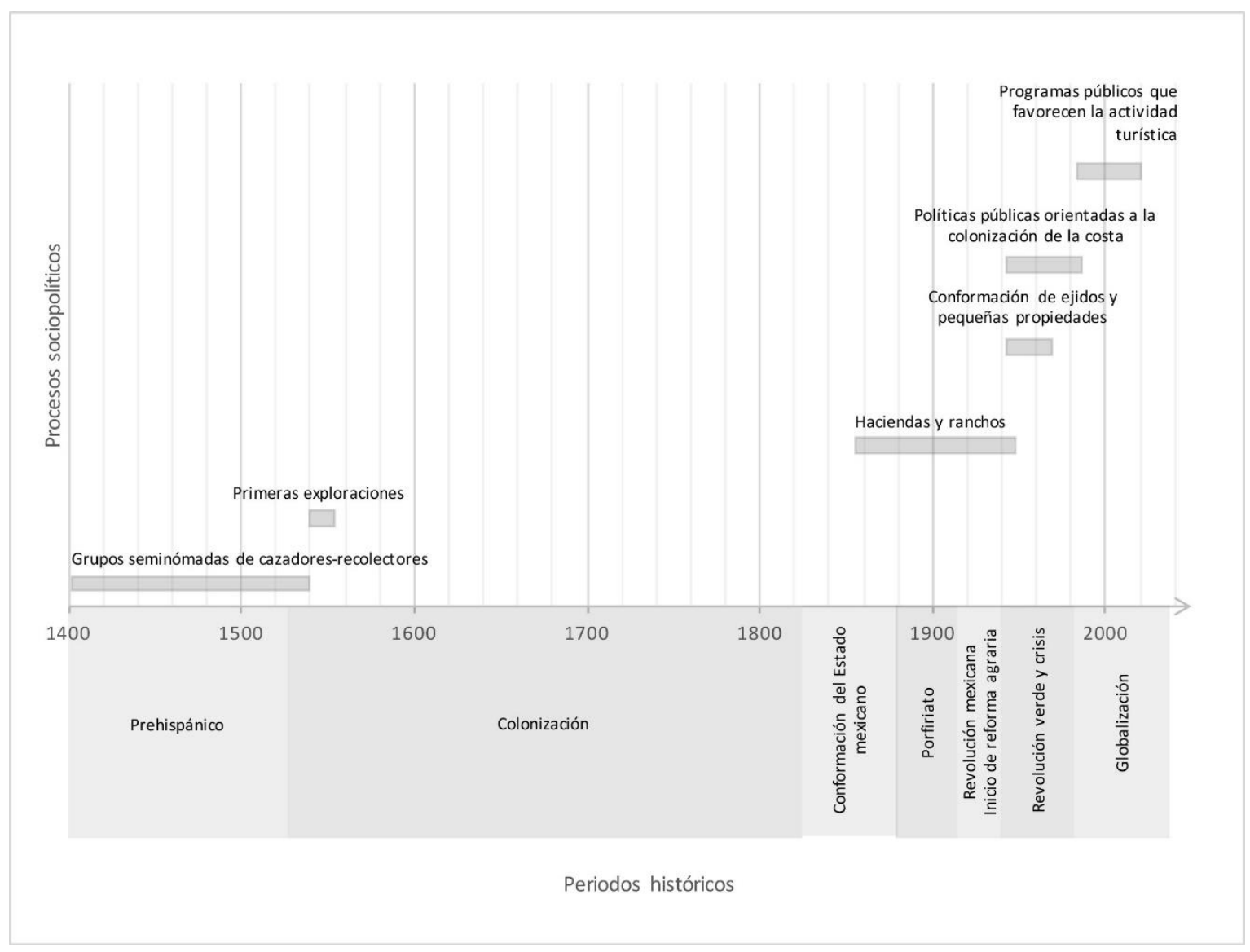

Fuente: elaboración propia.

Reasentamiento involuntario de los habitantes de Chamela

En el año de 1990, el gobierno del estado de Jalisco promovió el Corredor Turístico Ecológico Costa Alegre que pretendía fomentar acciones tendientes a lograr el desarrollo turístico del 
litoral jalisciense (Dachary 2004). Lo anterior, aunado a la reforma del artículo 27 constitucional en 1992, permitió la venta de terrenos ejidales como propiedad privada, dando pie a la promoción y apoyo para la ejecución de proyectos turístico-inmobiliarios, la mayoría de ellos, iniciativas de empresarios ya instalados en la zona que buscan expandir su dominio en la región (Ávila y Luna 20Iž, Martínez 2013).

Con este precedente, entre el 2005 y 2008, desarrolladoras turísticas sometieron a evaluación distintos proyectos que pretendían edificar extensas áreas de hoteles, campos de golf, marinas y zonas residenciales exclusivas, sobre la franja costera y los manglares aledaños a la Reserva de Chamela, como el de la Tambora (68I ha), Rancho San Andrés (746.7 ha), San Carlos y MarinaCareyes, que fueron rechazados por conflictos de intereses entre los empresarios (Ávila y Luna 2013). En el 2008, se propuso el proyecto Zafiro, en el cual unificaron las propuestas de La Tambora y San Carlos (con un total de gro ha), reformulando los aspectos ecológicos en el plan maestro, para cumplir con las demandas de las partes en conflicto involucradas.

Así, Zafiro se proyecta como un complejo turístico de gro ha, en las que habrá un campo de golf, zonas comerciales, clubes de playa y condominios, además de diferentes instalaciones hoteleras a las que sólo podrán ingresar personas con alto poder adquisitivo. La autoría de este proyecto pertenece al Grupo Invermar, un corporativo integrado por Operadora Chamela, S. de R.L. de C.V., Impulsora de Chamela, S.A. de C.V., Ecodesarrollos del Pacífico y Axolotl Inmobiliaria.

En el año 2oro, la Secretaría de Medio Ambiente y Recursos Naturales dictaminó positiva la Manifestación de Impacto Ambiental (MIA) del proyecto Zafiro, pasando por alto los

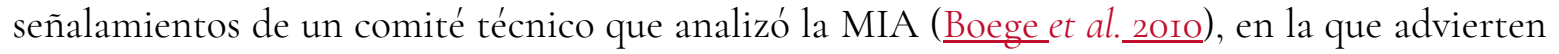
una serie de afectaciones ambientales y sociales. Estas últimas no tardaron en ser notorias porque, a pocos meses de la resolución, los pobladores de Chamela fueron desalojados de sus viviendas y comercios cercanos a la playa (Partida 20IO, Del Castillo 20II) un acontecimiento que describiremos a continuación.

\section{El reasentamiento del poblado de Chamela}

Después de la aprobación del plan maestro Zafiro, la primera maniobra para imponerse fue el desalojo del poblado de Chamela. A partir de la revisión de fuentes secundarias y de la información proporcionada por los informantes clave, ubicamos cinco etapas (véase figura z) en las que se llevó a cabo el reasentamiento. 
Figura 3. Etapas del reasentamiento del poblado de Chamela

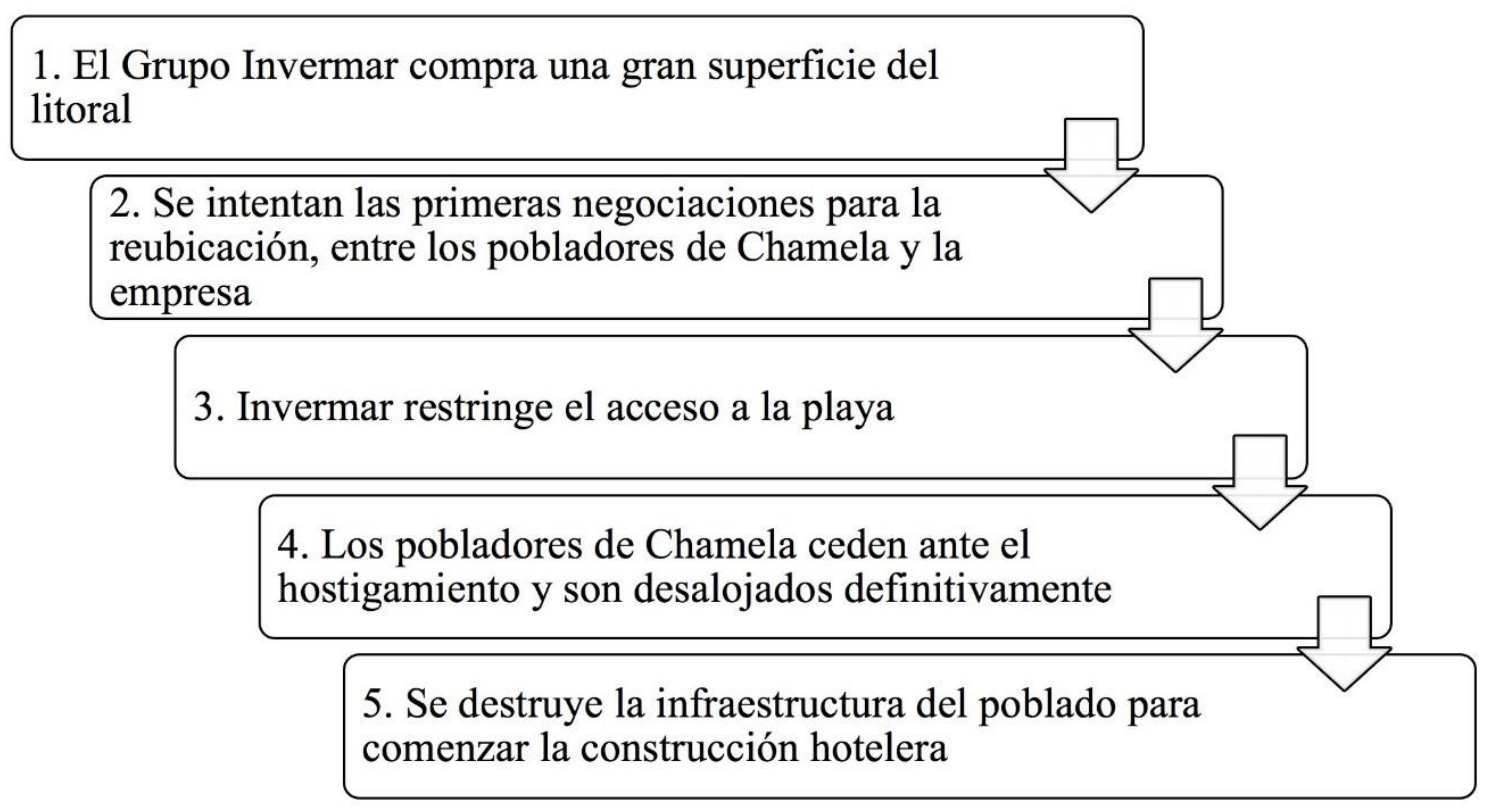

Fuente: elaboración propia.

Para el año 2008, el ya mencionado Grupo Invermar había comprado gran superficie de litoral (hasta aproximadamente 2,ooo ha) del municipio de La Huerta, dentro del que se encontraba el poblado de Chamela. Esta adquisición de terrenos se realizó gracias a la venta de las extensas propiedades privadas de las familias De Landeros y Urquiza. Con esta venta de terrenos, los pobladores de Chamela quedaron desprotegidos porque perdieron el permiso que los dueños anteriores les habían otorgado para habitar esos predios.

Fue hasta el año 20Io, una vez aceptada la MIA de Zafiro, que se llevaron a cabo las primeras reuniones entre los representantes de la empresa Impulsora Chamela (integrante del grupo Invermar encargada de ejecutar el proyecto) y miembros de la cooperativa de pescadores de Chamela, para comunicarles la construcción del complejo turístico, la inminente reubicación de poblado y el cierre de los restaurantes en la playa.

Como la primera vez que los pescadores escucharon la noticia de que serían reubicados se negaron a negociar, la empresa comenzó una serie de amenazas y acciones intimidatorias hacia los pobladores. En primer lugar, instalaron una caseta con vigilancia y construyeron un portón para obstruir el camino de entrada a la playa tanto al turismo como a los mismos habitantes locales, los cuales no dudaron en manifestar su inconformidad y buscar abogados que los ampararan.

La empresa, al ver la resistencia de los locatarios, decidió convocar otra reunión, esta vez presidida por uno de los dueños y principal inversionista del Grupo Invermar, el alemán 
Wolfgang Hahn. Los pobladores entrevistados comentan que el discurso de Wolfgang fue muy persuasivo porque les dijo que el complejo turístico traería beneficios a la comunidad como oportunidades de empleo, clases de idiomas, nuevas lanchas para el turismo, todo a cambio de que no estuvieran las ramadas (los restaurantes en la playa) ni las viviendas.

Después de esta reunión, las familias cedieron abandonar sus hogares y los restaurantes a cambio de recibir una compensación económica y las promesas mencionadas. Quienes más se resistieron al desalojo, se les hostigó colocando cercos alrededor de sus casas o disparando con armas de fuego sus negocios, algunos fueron encarcelados. Finalmente, la mayoría se resignó a la reubicación que, de acuerdo a sus expresiones, fue "más a fuerzas que nada, porque si no lo aceptabas de todos modos te iban a quitar".

Las compensaciones económicas se diferenciaron según el tipo de propiedad afectada, es decir, a los pescadores con restaurantes se les ofreció una cantidad de dinero (aproximadamente 400 mil pesos); a quienes ya contaban con propiedades más grandes se les ofreció la construcción de sus casas en espacios aledaños a la carretera.

A principios del año 20II, los pobladores de Chamela fueron completamente desalojados. Las familias, sin muchas opciones para su reubicación, optaron por vivir a ambos lados de la Carretera Federal 200 (véase mapa 2), en predios que ya tenían tiempo siendo habitados con algunas viviendas dispersas. Volvieron a construir sus casas en frágiles condiciones y materiales como palos y lonas, por las cuales sufrieron estragos en dos fenómenos naturales importantes: el huracán Jova, en el 20Ir, que inundó sus casas, y el huracán Patricia, en el 2015, que derrumbó sus viviendas por completo. 
Mapa 2. Ubicación actual de la localidad de Chamela

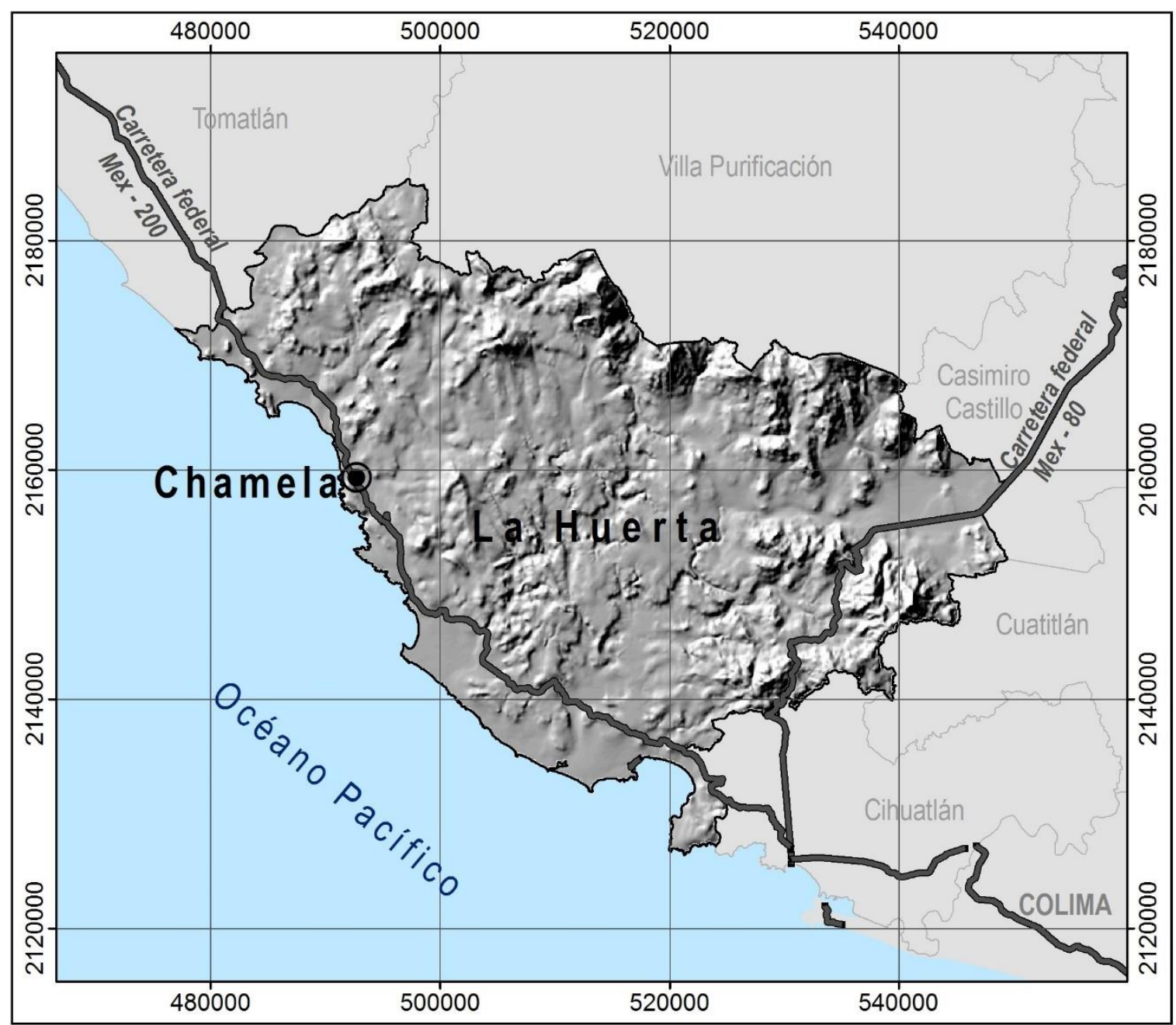

Elaborado por Óscar Balcázar Medina y Juan Manuel Rodríguez Gómez, DERN, CU Costa sur, Universidad de Guadalajara.

Finalmente, después del desalojo definitivo, la empresa Impulsora destruyó toda la infraestructura restante y restringió completamente el paso a las playas La Virgencita y Boca de Chamela, colocando vigilantes y guardias de seguridad en los caminos de entrada. Así, los turistas ya no se acercaron y los residentes locales no frecuentaron espacios que antes formaban parte de su cotidianidad. En la figura 4 se presenta una línea del tiempo de los sucesos más relevantes que dieron lugar al desalojo y reasentamiento del poblado de Chamela a lo largo de las últimas décadas. 
Figura 4. Factores políticos, sociales y climáticos que influyeron en el reasentamiento del poblado de Chamela

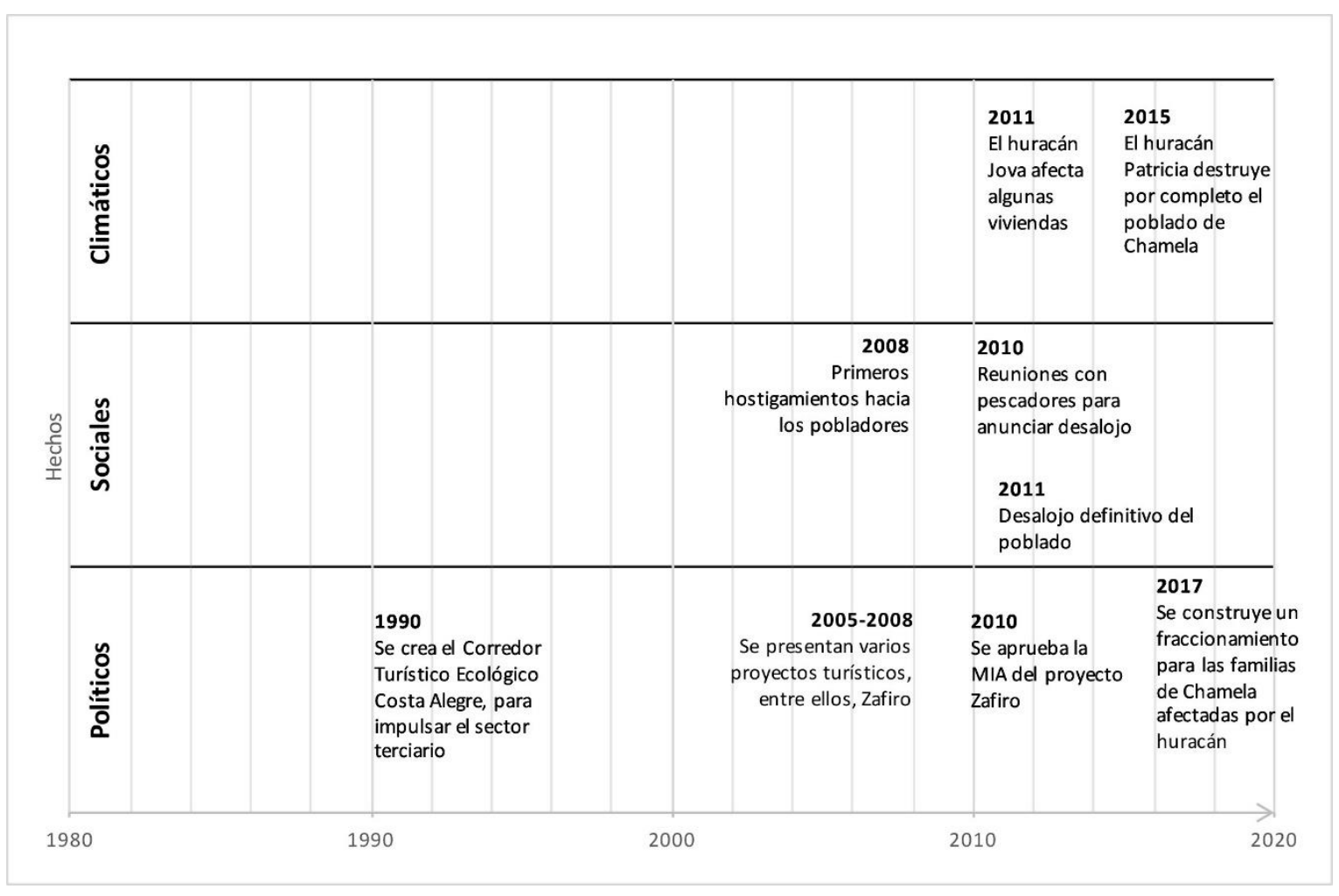

Fuente: elaboración propia.

El poblado de Chamela en la actualidad

Desde el reasentamiento del poblado, los habitantes de Chamela viven con la incertidumbre respecto a cuáles serán sus medios de vida. Lo único que ahora se les permite es realizar la actividad pesquera, para la cual deben acatar un reglamento restrictivo que los empresarios les imputaron por estar en su propiedad privada. Uno de los entrevistados nos comparte su sentir con las siguientes palabras "lo único bueno de lo malo que hubo fue nos que quedamos haciendo lo que sabemos hacer [...] nosotros no sabemos hacer otra cosa más que pescar, si me quitas eso me vas a mandar a otro lado".

Actualmente, la mayor parte de los productos que pescan la venden a un intermediario de la localidad, otra parte la comercian entre los vecinos o gente que llega esporádicamente y, por último, destinan una fracción para autoconsumo. Cuando hay buena temporada de pesca congelan una cantidad como reserva para las épocas de escasez. No obstante, pese a estas estrategias de subsistencia, muchos integrantes de las familias de pescadores optaron por migrar a localidades cercanas $u$ otras ciudades, a trabajar en oficios como servidumbre en hoteles o mano de obra en construcciones. 
El reasentamiento, provocó otras problemáticas, la más relevante es la que surgió después del paso del huracán Patricia en el año 2015, que derribó casi todas las viviendas, evidenciando el estado de vulnerabilidad en el que se encontraban. Como medida restaurativa, el gobierno construyó un fraccionamiento habitacional, que entregaron a las aproximadamente cincuenta familias afectadas. Lo anterior aumentó la demanda de servicios como el agua potable, la energía eléctrica, el gas y, por lo tanto, los gastos correspondientes al pago de estos servicios, que las familias tienen que solventar.

\section{Percepciones sociales de los pobladores de Chamela}

Los entrevistados expresan una serie de emociones y posturas respecto a todo lo que han vivido con el reasentamiento; es recurrente escuchar la incertidumbre que sienten al desconocer cuáles serán sus medios de subsistencia los próximos años, en el mismo plano, manifiestan la desaparecida sensación de libertad para actuar y decidir, sobre todo, porque tienen restringido el acceso a la playa, un paisaje que antes formaba parte de su vida cotidiana y al que ahora sólo tienen acceso para pescar.

Las mujeres, en particular, perdieron su autonomía financiera porque ya no cuentan con los ingresos de los restaurantes que antes administraban; situación que repercute en la economía de toda la unidad familiar. Conforme pasa el tiempo, los pescadores pierden la esperanza de que con el nuevo complejo turístico tendrán trabajo, que se les seguirá permitiendo pescar y que les construirán un embarcadero. Con la expresión "nosotros ya hasta a lo frío le soplamos", nos transmiten la desconfianza que sienten ante las nuevas promesas.

En contraste con los sentimientos anteriores, experimentan mayor seguridad porque ahora ya tienen viviendas de cemento y cuentan con la titularidad de su propiedad, condición que antes no podían disfrutar. Sin embargo, los gastos ahora son más porque tienen que pagar los servicios de luz, agua, gas, teléfono y televisión. No obstante, recuerdan que anteriormente contaban con más espacio que les permitía tener árboles, plantas comestibles y hasta animales de corral como gallinas, por lo que tenían otro tipo de alimentos, y no gastaban en ellos.

Respecto a la convivencia hay posturas opuestas, algunos sienten que ahora es mayor la convivencia porque las viviendas están más cerca, otros perciben que eran menos cohibidos entre ellos pese a que vivían más distantes. Lo que si fue inevitable, fue la ruptura de relación entre familias que apoyaban la reubicación y de quienes empezaron a sospechar que recibían ciertos incentivos de los empresarios.

En lo que concierne a los avances en la construcción del complejo hotelero, mencionan que aunque no hay muchos avances visibles, han observado que han quitado mangles reforestando con otra vegetación distinta a la local y que secaron la laguna junto al mar, para ello ya tienen trabajadores de otras localidades, algo que les genera resentimiento porque se preguntan "¿por qué no nos contratan a nosotros que no tenemos trabajo y somos de la población más cercana?"

Los desplazados de Chamela transitan entre sentimientos y emociones antagónicas, desde la incertidumbre, la desconfianza, la desmoralización hasta la seguridad por tener las escrituras de 
un hogar. El enunciado de una de las entrevistadas expresa lo que de manera general compartieron en las charlas la mayoría de sus compañeros: "pues extraño allá [vivir cerca del mar] porque como que allá vivía con más libertad, por lo menos, ira, en el mar se relaja uno bien a gusto ni sientes el día [...] a mí se me hacía bonito, se me hacía como que era más, más extendido mi modo de vivir. Y aquí, pues, no ira, aquí como que estamos diario más oprimidas por decirlo as'́".

\section{Discusión y conclusión}

Analizar el turismo desde el enfoque crítico de la Ecología Política, nos permite entender los eventos colaterales que surgen a partir de la introducción, y muchas veces imposición, de esta actividad en los espacios rurales. En el caso del complejo turístico Zafiro, queda claro que es un proyecto que está diseñado para una clase socioeconómica alta, elitista y excluyente.

A la par, fue necesario entender el tema de los reasentamientos por proyectos de desarrollo, el cual se ha convertido en el mecanismo para despojar a las comunidades de sus territorios. En particular, el reasentamiento de Chamela forma parte de un fenómeno más amplio de desplazamientos por megaproyectos turísticos en la costa jalisciense; proceso que genera las condiciones de desigualdad social que alimenta la maquinaria capitalista.

Retomando lo presentado en la tabla 2, para el poblado de Chamela, pudimos distinguir los siguientes impactos y consecuencias derivados del reasentamiento, que representamos en la tabla 3.

Tabla 3. Impactos generados por el reasentamiento del poblado de Chamela

\begin{tabular}{|c|c|c|}
\hline Dimensión & Impactos/afectaciones & Consecuencias \\
\hline Social & $\begin{array}{l}\text { - Se dispersan los grupos de } \\
\text { parentesco y los sistemas } \\
\text { familiares, debido a la migración } \\
\text { para encontrar otras fuentes de } \\
\text { empleo. } \\
\text { - Se desintegran las redes sociales } \\
\text { informales y las asociaciones } \\
\text { formales, como la convivencia que } \\
\text { había entre los pescadores con las } \\
\text { familias de la comunidad y } \\
\text { vecinos. }\end{array}$ & $\begin{array}{l}\text { - Debilitamiento de la } \\
\text { cohesión social: intra e } \\
\text { interfamiliar } \\
\text { - Aumenta la tensión } \\
\text { psicológica: } \\
\text { incertidumbre, } \\
\text { desconfianza }\end{array}$ \\
\hline Cultural & $\begin{array}{l}\text { - Se abandonan espacios simbólicos, } \\
\text { al dejar de frecuentar el mar y no }\end{array}$ & \\
\hline
\end{tabular}




\begin{tabular}{|c|c|c|}
\hline & $\begin{array}{l}\text { sentirse con la libertad de ir a la } \\
\text { playa. } \\
\text { - Se quiebra el vínculo físico y } \\
\text { psicológico con el pasado. } \\
\text { - Se borran las raíces de la identidad } \\
\text { cultural de la población, esto } \\
\text { pasará eventualmente cuando los } \\
\text { pescadores comiencen a realizar } \\
\text { otros oficios. }\end{array}$ & \\
\hline Económico & $\begin{array}{l}\text { - Se desmantelan los sistemas de } \\
\text { producción. } \\
\text { - Se interrumpen los nexos } \\
\text { comerciales entre productores y } \\
\text { consumidores } \\
\text { - Se desorganiza la forma de } \\
\text { comercio local. }\end{array}$ & $\begin{array}{l}\text { - Disminuyen sus } \\
\text { estrategias de } \\
\text { subsistencia } \\
\text { - } \quad \text { Inseguridad } \\
\text { alimentaria } \\
\text { - Empobrecimiento }\end{array}$ \\
\hline
\end{tabular}

Fuente: elaboración propia

El desmantelamiento que han vivido los habitantes de Chamela de sus medios de vida, es parte de la estrategia de despojo por parte de las empresas hoteleras, que buscan generar una total dependencia de los precarios empleos que les ofrecen, como única puerta de salida a sus problemas financieros. Pero cabe recordar, que el agravio no es sólo económico, también lo es cultural y social, porque hay ruptura o como menciona Cernera (200I) un desgarramiento interno en la comunidad que es complicado zurcir.

Sumado a los impactos, encontramos la vulnerabilidad en la que vivieron durante casi seis años desde el 20ir hasta el 20i6, un lapso en el que fueron afectados por el paso de dos huracanes de alta categoría, de los cuales el del 2015 fue el más devastador; una conyuntura que los gobiernos estatal y municipal, y el corporativo hotelero, aprovecharon para aparecer como benefactores, construyendo un fraccionamiento habitacional para los afectados, siendo ellos mismos los impulsores del despojo. Las casas edificadas, si bien cumplen con algunos estándares de vivienda, omitieron por completo otorgar espacios amplios de traspatio en los que pudieran contar con la diversa vegetación de árboles, arbustos, hortalizas y animales, que solían tener antes.

Por todo lo anterior, las familias de Chamela, la mayoría dedicadas a la pesca como actividad principal, conviven entre un contraste de emociones y pensares. No debemos olvidar que ellos y ellas son quienes cuentan con un conocimiento específico sobre el mar, un mar que durante muchos años fue su casa y su fuente de vida, un mar que les fue negado y junto con él, se van sus saberes, ésos que sólo se aprenden con la experiencia de sumergirse en sus aguas profundas y 
atravesar sus olas impredecibles. Ahora tienen que navegar en otro tipo de aguas, en las aguas de la incertidumbre, del miedo y la desconfianza. ¿Quién velará por ellos? ¿Los proyectos turísticos de corte neoliberal que sólo favorecen a una clase? ¿Un gobierno coludido con las empresas? ¿Qué sigue y quién sigue?

Bibliografía

AGUILAR, Arturo, Alejandro PALAFOX y Julis ANAYA. 2015. "El turismo y la transformación del paisaje natural”. Noésis. Revista de Ciencias Sociales y Humanidades (24): 19-29.

ÁVILA Patricia y Eduardo LUNA. 2013. "Del ecologismo de los ricos al ecologismo de los pobres". Revista Mexicana de Sociología 75(I): 63-89.

BOEGE, Karina, Alicia CASTILlO, Andrés GARCÍA, Jorge VEGA, Álvaro MIRANDA, Angelina RUIZ y Rafael RUEDA. 20Io. Dictamen técnico de la manifestación de impacto ambiental del proyecto de desarrollo turístico "Zafiro" (clave: 14JA2009Too17): identificación de posibles impactos a las áreas naturales protegidas de la región. México: Universidad Nacional Autónoma de México, Fundación Ecológica de Cuixmala, A.C.

BYE, Robert, Luis CERVANTES y Beatriz RENDÓN. 2002. "Etnobotánica en la región de Chamela”. En Historia Natural de Chamela, ed. Felipe Noguera, Jorge Vega, Alfonso García y Mauricio Quesada, 545-559. México: Instituto de Biología, Universidad Nacional Autónoma de México.

CAÑADA, Ernest. 20I6. "Implicaciones socioambientales de la construcción del espacio turístico". Ecología Política Cuadernos de Debate Internacional (52): I2-I6.

CAÑADA, Ernest y Jordi GASCÓN. 2or6. "Urbanizar el paisaje: turismo residencial, descampesinización, gentrificación rural. Una introducción”. PASOS, Revista de Turismo y Patrimonio Cultural y Foro de Turismo Responsable (I6): 5-36.

CASTILlO, Agustín. 20io. "La historia de Jalisco y sus habitantes, historias de gente, biodiversidad y ecosistemas". 3 C Conocimiento+Cultura+Ciencia (4): 39-46

CASTILlO, Alicia, Antonieta MAGAÑ, Anna PUJADAS, Lucía MARTÍNEZ y Carmen GODÍNEZ. 2005. "Understanding the Interaction of Rural People with Ecosystems: A Case Study in a Tropical Dry Forest of Mexico". Ecosystems (8): 630-643.

CEBALlOS, Gerardo y Andrés GARCÍA. 20io. "Chamela-Cuixmala, Jalisco y Colima". En Diversidad, amenazas y áreas prioritarias para la conservación de las selvas secas del oeste de México, ed. Gerardo Ceballos, Andrés García, Lourdes Martínez, Eduardo Espinosa, Juan Bezaury y Rodolfo Dirzo, 44I-446. México: Comisión Nacional para el Conocimiento y Uso de la Biodiversidad, Universidad Nacional Autónoma de México. 
CERNEA, Michael. 200I. Reasentamiento de población y estudios sociales. Washington, DC: Banco Mundial.

COMPOSTO, Claudia. 2oro. "Acumulación por despojo y neoextractivismo en América Latina. Una reflexión crítica acerca del Estado y los movimientos socio-ambientales en el nuevo siglo". Astrolabio, Nueva Época (8): 323-352.

CORDERO, Allen, Daniel HIERNAUX-NICOLAS, Luisa VAN DUYNEN. 20o2. Imaginarios sociales y turismo sostenible. Cuaderno de Ciencias Sociales (I23). San José: Facultad Latinoamericana de Ciencias Sociales (FLACSO), Sede Costa Rica.

CRUZ, Erika, Lilia ZIZUMBO, Graciela CRUZ y Ana QUINTANILLA. 2or2. "Las dinámicas de dominación capitalista en el espacio rural: la configuración de paisajes turísticos". Cuadernos de Desarrollo Rural 9(69): I5I-I74.

DACHARY, Alfredo y Stella ARNAIZ. 2004. Desarrollo y Turismo en la Costa de Jalisco. México: Universidad de Guadalajara.

DEL CASTILlO, Agustín. 20ir. Proyecto Zafiro crece entre la polémica. Público, 3i de julio de 20Ir. https://cronicadesociales.org/20II/o7/3i/proyecto-zafiro-crece-entre-la-polemica/

FENNER, Gabriela. 20I2. "Reubicación poblacional como estrategia de ordenamiento territorial: tres casos en Chiapas". En Corografía y escala local. Enfoques desde la geografía cultural, ed. Federico Fernández y Pedro Urquijo, 59-79. Morelia: Centro de Investigaciones en Geografía Ambiental (CIGA), Universidad Nacional Autónoma de México, izo p.

FLETCHER, Robert. 20i6. "Tours caníbales puesto al día: La ecología política del turismo". Ecología Política Cuadernos de Debate Internacional (52): 26-34.

HARVEY, David. 2004. "El 'nuevo' imperialismo: acumulación por desposesión". Socialist Register: 99-I29. https://cronicon.net/paginas/Documentos/No.22.pdf

INEGI. 20io. "Censo de población y vivienda 20го". http://www3.inegi.org.mx/sistemas/scitel/Default?ev=5 (Fecha de consulta: o3 de noviembre de 2017).

MACÍAS, Jesús. 200I. "La reubicación del riesgo". En Reubicación de comunidades humanas. Entre la producción y la reducción de desastres, ed. Jesús Macías, 25-46. México: Universidad de Colima.

MALDONADO, Oscar, Luis FLORES, Rosa CHÁVEZ y Myrna BRAVO. 2015. "El turismo como actividad complementaria de la pesca en comunidades rurales. Caso Bahía de Chamela, Jalisco". Spanish Journal of Rural Development 6(I): 83-92.

MARTÍNEZ-ALIER, Joan. 2006. "Los conflictos ecológico-distributivos y los indicadores de sustentabilidad". Polis, Revista Latinoamericana (I3): I,I5. 
MARTÍNEZ, Lucía. 2003. "Percepciones sociales sobre los servicios ecosistémicos en dos comunidades aledañas a la Reserva de la Biósfera Chamela-Cuixmala". Tesis de Licenciatura, Universidad Michoacana de San Nicolás de Hidalgo, Facultad de Biología.

MARTÍNEZ, Virginia. 2orz. "La otra Costa': Procesos de históricos de apropiación territorial de la Costa de Jalisco (I9r7-2oro)". Tesis de Doctorado, Universidad de Guadalajara, Centro Universitario de Artes, Arquitectura y Diseño.

MARTÍNEZ, Paulina y Antonio CORGOS. 20i4. "La pesca artesanal en Jalisco. Conflictos en torno a la conservación biocultural y la reproducción del capital. El caso de Careyitos". Sociedad y Ambiente I(4): 23-38.

MOUNTJOY, Joseph. 2015. "La colonización del lejano Occidente de México por agricultores sedentarios durante el Formativo medio, izoo a 400 a.C.". Revista Occidente (junio): I-I8.

NAVAS, Grettel y Macià BLÁZQUEZ. 20i6. "El turismo bajo las lógicas del capital: Entrevista a Ivan Murray Mas". Ecología Política Cuadernos de Debate Internacional, (52): 12-16.

PALAFOX, Alejandro, Delfino MADRIGAL y Lilia ZIZUMBO. 20II. "Apropiación, funcionalización y homogeneización del espacio para el desarrollo turístico de Quintana Roo, México". Cuaderno Virtual de Turismo iI(2): 282-293.

PARTIDA, Juan. 2oIo. "Entre la intimidación y el despojo, sigue en marcha el complejo turístico Zafiro". Crónica de Sociales, 24 de marzo de 20Io. https://cronicadesociales.org/20Io/o3/24/entre-la-intimidacion-y-el-despojo-sigue-enmarcha-el-complejo-turistico-zafiro

PAZ, Ma. Fernanda. 20I2. "Deterioro y resistencias. Conflictos socioambientales en México". En Conflictos socioambientales y alternativas de la sociedad civil, ed. Darcy Tetreautl, Heliodoro Ochoa-García y Eduardo Hernández-González, 27-47. Guadalajara: Instituto Tecnológico y de Estudios Superiores de Occidente.

Proceso. 1997. La Redacción. "En diez años se hizo hasta de su propia reserva ecológica en la costa jalisciense". 5 de abril de i997. http://www.proceso.com.mx/I75249/en-diez-anos-se-hizohasta-de-su-propia-reserva-ecologica-en-la-costa-jalisciense

ROUX, Rhina. 20i2. "México: despojo universal, desintegración de la república y nuevas rebeldías". Theomai (26). http://revista-theomai.unq.edu.ar/NUMERO\%2026/Roux\%20\%20M\%C3\%Agxico.pdf

SMITH, Oliver. 200I. "Consideraciones teóricas y modelos del reasentamiento de comunidades". En Reubicación de comunidades humanas. Entre la producción y la reducción de desastres, ed. Jesús Macías, 47-6o. México: Universidad de Colima. 
SVAMPA, Maristella. 20II. "Extractivismo neodesarrollista, gobiernos y movimientos sociales en América Latina”. Problèmes d'Amérique Latine (80).

VICTORIA, Ma. Irene y Carlos MOLINA. 2003. "Reasentamiento involuntario: integración y civilización". Revista Bitácora Urbano Territorial I(7): 19-25.

VILCHIS, Adrián, Lilia ZIZUMBO, Neptalí MONTERROSO, Emilio ARRIAGA y Alejandro PALAFOX. 20I6. "Dinámicas capitalistas para la acumulación por despojo". Revista Ciencias Sociales Universidad de Costa Rica I5I(I): 3I-4I.

\section{Notas}

I Proyecto Sociología del Manejo de los Recursos Naturales. Convocatoria interna del Centro Universitario de la Costa Sur, Universidad de Guadalajara.

\section{Esmeralda Azucena Mastache De los Santos}

Maestra en Ciencias en Manejo de Recursos Naturales, Universidad de Guadalajara, Centro Universitario de la Costa Sur (CUCSUR). Actualmente: Investigadora Independiente. Líneas de investigación: Agroecología y Ecología Política, en Organizaciones Campesinas y de Educación Popular. Últimas publicaciones: A. Mastache, P. Gerritsen y J. Morales. 2018. "Multifuncionalidad de la agricultura campesina en San Miguel Cuyutlán en el Área Metropolitana de Guadalajara, Jalisco". En Los espacios rurales y la ciudad: agriculturas periurbanas y sustentabilidad en el Área Metropolitana de Guadalajara, México. Colección Complexus. Saberes Entretejidos, coord. J. Morales, 59-7r. México: ITESO; J. Morales, H. Ochoa, L. Velázquez, A. Mastache, E. Cervantes, A. Becerra. 20r8. "La agricultura periurbana multifuncional y sus aportaciones hacia la sustentabilidad regional en la zona metropolitana de Guadalajara, Jalisco, México". En Multifuncionalidad, sustentabilidad y buen vivir. Miradas desde Bolivia y México. Colección Manantlán, coord. P. Gerritsen, S. Rist, J. Morales y N. Tapia, 273-312. México: CU CostaSur Grana; P. Gerritsen, P. Beas, A. García, M.J. Garibay, R. González, A. Mastache, S. Ortiz, A. Rojo y C. Topete. 2015. "Instituciones, programas de desarrollo rural y campesinos: estudio de caso del valle Autlán-El Grullo, región Sierra de Amula de Jalisco, Occidente de México". Sociedades Rurales, Producción y Medio Ambiente I5(29).

\section{Peter R.W. Gerritsen}

Doctor en Ciencias Sociales, Wageningen University \& Research, Los Países Bajos. Adscripción institucional: Profesor Investigador Titular "C", Departamento de Ecología y Recursos Naturales, Centro Universitario de la Costa Sur, Universidad de Guadalajara. Líneas de investigación: Sociología Rural, Agroecología y Manejo de Recursos Naturales. Últimas publicaciones: C.A. Osorio-Estrella, A. Acosta-Robles, J.Á. Amaral-Rodríguez y P.R.W. Gerritsen. 2019. "Seguir en la siembra': identidad y motivación campesina en la región Sierra de Amula en el sur del estado de Jalisco". Sociedades Rurales. Producción y Medio Ambiente r9(37): 95inz; P.R.W. Gerritsen, V. Sánchez Bernal y G. Torres Rodriguez. 2019. "La cara oculta de la seguridad alimentaria'. Estudio de caso del sur del Estado de Jalisco, Occidente de 
México". Brazilian Journal of Development 5 (7) (julio): 7569-7585; J.P. Esparza-Carlos, P.R.W. Gerritsen, S.A. López-Parraguirre, M. D. García Rojas y J.L. Peña-Mondragon. 2019. "Como perciben los niños el jaguar, Panthera onca (Carnivora: Felidae) in Jalisco, México". Revista de Biología Tropical: International Journal of Tropical Biology and Conservation 67(2) (junio). DOI I0.15517/RBT.V6712.33894. 